\title{
Examining the Direct Effect of the Use of Traffic Safety Technologies in Abu Dhabi Highways on Other Traffic Safety Dimensions
}

\author{
Musallem M. Al Junaibi \\ Abu Dhabi Police and University of Wolverhampton, Wolverhampton, UK \\ Email: m80000435@zu.ae \\ Panos Georgakis and Sabah Mushatat \\ University of Wolverhampton, Wolverhampton, UK \\ Email: $\{$ P.Georgakis, S.Mushatat $@ @$ wlv.ac.uk
}

\begin{abstract}
This paper presents the findings of a study, implemented in Abu Dhabi, which aimed to examine the direct effects of the use of traffic safety technologies on the mitigation of risks associated with traffic accidents. The study adopted the use of a questionnaire-based survey with traffic safety experts in Abu Dhabi Emirate. The views of more than a hundred respondents were collected on areas such as the status of existing traffic safety technologies in Abu Dhabi's highway network, the impact of traffic safety technologies on enforcement, existing highway design practices, effects of driver education on safety and the impact of safety technologies on the efficiency of emergency responses. Factor analysis and Freidman tests were employed for the interrogation of the data in order to extract findings from the views of different experts on the aforementioned areas. The analysis showed that the deployment of traffic safety technologies has a positive impact on the efficiency of enforcement practices and improvements on traffic safety, and on enhancing operators efficiency and capability in taking appropriate and prompt action in situations calling for emergency responses. Moreover, speed cameras and VMS deployment are highly favoured in addressing engineering design shortfalls. Also, training and awareness enhance the efficiency and effectiveness of traffic safety technologies.
\end{abstract}

Index Terms-traffic safety, traffic safety technologies, uae, abu dhabi, highways, serious road traffic accidents, intelligent transport systems, road safety factors, traffic safety dimensions.

\section{INTRODUCTION}

Road traffic accidents, especially serious accidents, contain a sense of foreboding and threaten to overwhelm humanity as they negatively impact the necessary daily activities involving transportation of people and goods. Usage of vehicles becomes risky if individual drivers do not employ them well and safely, and for the reasons they were designed for. Traffic regulations and enforcement have been enacted to achieve safety and security for all

Manuscript received January 1, 2017; revised June 12, 2017. road users. The design of safe roads accompanied by regular traffic safety audits has became a priority in reducing the occurrence of serious accidents. Vehicle and driver safety, driver training and education, emergency responses and regular evaluation of their performance are important factors in any traffic safety strategy.

\section{LITERATURE REVIEW}

\section{A. Legislation and Enforcement}

Since the main goal of the legislation is to reduce collisions, Ảberg [1] argues that rules in road traffic are necessary because, generally, drivers cannot be expected to learn through their own experiences about the negative consequences of behaviour. According to the previous review, enforcement is also needed to increase the effects of safety rules and must be visible to be effective. During the 1990s, the development of the infrastructure in Abu Dhabi was moving at a pace which caused increases in journey distance, drivers, and vehicles. With the subsequent increasing collision rates, the Ministry of the Interior (MoI) was motivated to co-ordinate the first Federal Traffic Legislation and introduced Law 21 (1995) which is the fundamental law for traffic and road safety legislation within the whole UAE. In 2007, a further revision of the law was provided that increased the maximum penalty from AED 500 to 3000, and fixed fines for 147 different fixed penalty violations. This also included the introduction of the black point system. In regard to the effectiveness of enforcement technologies, the findings of Greg Chen et al. [2] suggest that the British Columbia photo radar programme has improved safety and reduced speed at the photo radar deployment locations. As a whole, the effects extended across the $22 \mathrm{~km}$ study corridor. The mean traffic speeds were reduced to below posted speeds at the times and precise locations where it was operating. Traffic speeds remained at the reduced level over the two-year study period. Moreover, traffic speed also declined nearby, in the absence of radar enforcement. The percentage of 
excessively speeding vehicles fell significantly, as indicated at the high end in speed distribution by the slimmer tails.

In northern Kosovo, drivers seemed to support the application of the new traffic enforcement technologies (e.g. speed cameras, speed limitation devices and devices to prevent driving under the influence of alcohol), while the lack of enforcement seems to influence the configuration of attitudes toward speeding and the violation of traffic laws. Therefore, it is likely that devices would result in major improvements in traffic safety [3]. However, according to De Pauw et al. [4], the installation of speed cameras has had a positive effect on traffic safety, in particular on severe crashes. At locations with a lower speed limit, the cameras seem to generate greater effects. Furthermore, speed cameras are an effective measure to improve traffic safety at locations with a high number of speed violations. Moreover, the installation of the point-to-point speed enforcement system on the urban motorway, A56, led to very positive effects on both speed and safety. As far as the safety effects are concerned, the P2P system yielded a 32\% reduction in total crashes, with a lower $95 \%$ confidence limit of the estimate equal to $22 \%$. The greatest crash reductions were produced in rainy weather $(57 \%)$, on wet pavement $(51 \%)$, on curves $(49 \%)$, for single-vehicle crashes $(44 \%)$, and for injury crashes $(37 \%)$. It is noteworthy that the $\mathrm{P} 2 \mathrm{P}$ system also produced a statistically significant reduction of $21 \%$ in total crashes in the part of the motorway where it was not activated $(22.3 \mathrm{~km}$ vs. $18.1 \mathrm{~km})$, thus generating a significant spillover effect [5]. Also, in 2006, the city of Scottsdale, Arizona, implemented a nine-month pilot programme to evaluate the feasibility and effects of highly visible speed camera enforcement on a busy urban freeway. Deployment of six cameras along an eight-mile corridor was associated with large declines in mean speeds and an $88 \%$ decrease in the chances of vehicles traveling $11 \mathrm{mph}$ or more above the speed limit. Traffic speeds increased soon after the pilot programme was suspended. In addition to the above, speed cameras were associated with large reductions in speeding on the same highway, but 25 miles away from the camera installations [6].

\section{B. Engineering}

In relation to road safety engineering, the management of horizontal curves was also considered in the New Zealand study by Charlton [7]. The study indicates how driver errors related to horizontal curves were caused by three related issues - failure in driver attention, miscalculation on speed and curves, and improper lane positioning. The study indicated how advance warning signs on their own are not as effective in decreasing speed, as when they are used in combination with chevron sight boards and/or repeater arrows. Additional to that, Montella et al.'s [5] study on the urban motorway A56, show that the effect of speed on safety is greater on curves and for injury crashes. These crash modification functions allow the quantification of the safety effect of the speed changes, even though they are affected by some limitations. Estimates of the speed values in the different observation periods are based on accurate measurements of the average travel speeds of each vehicle crossing the enforced sections before and after the system's activation. In general, there are few studies which have specifically covered road safety practices in Abu Dhabi. The majority of the studies on road safety practice have covered the entire United Arab Emirates. Castle et al. [8] also discuss how the use of road safety strategies, the Crash Analysis Reporting System (CARS), the review of design standards, the development of Road Safety Audits (RSAs), and a safety assessment of the road proportion network have been able to decrease road accidents. The Abu Dhabi Police and DOT have reviewed the traffic impact studies in order to evaluate new developments, to review designs of new roads, to prepare specific traffic studies, to issue permission for temporary traffic management, and to manage truck restrictions. Bener and Alwash [9] also sought to evaluate how high-speed driving of motor vehicles impacts on traffic safety in the UAE. The authors revealed that with the use of radar systems and speed cameras in 1994 in the UAE, speeding levels were significantly reduced. Moreover, the monitoring radar systems and video cameras also decreased road accidents and deaths. With reduced speeding in the country, road accidents were decreased. The authors recommended a combination of remedies in order to reduce these road accidents. These remedies included decreasing the speed of driving and the use of seatbelts.

\section{Education}

The human element is the main cause of accidents, not only at the local level, but all over the world. This fact is one of the fundamentals of the science of investigation in traffic accidents and the results of the theoretical, practical, and technical analyses, particularly honourable ones [10]. In an Australian study, Christie [11] assessed the international literature on the efficacy of driver training as a part of road safety. In general, his study evaluated the safety value in the programmes for three specific groups: learner drivers, young/recently licensed drivers, and experienced drivers. His review indicated that for learner drivers, the pre-licence education does not assist post-licence reductions in crashes. Also, no drivers care much about campaigns to raise awareness of traffic dangers. The reason behind this is due to the styles of such campaigns, which often address the driver or road user in an ordering style (do this to avoid this) without including enough persuasion, grading in language of communication, or specifying the target group to receive the message. Parkes et al. [12] discuss that the driver training and education situation in Abu Dhabi enjoys benefits from the presence of the Emirates Driving Company, created in 2000. This company carried out contracts with SweRoad to secure a base for a comprehensive driver education programme. Currently, EDC offers theory training for light vehicles, heavy vehicles, heavy buses, and motorcycles, with the initial stages of practical training for light vehicles. Since the 
beginning of 2013, Abu Dhabi Police has started carrying out 20 traffic programmes, so the awareness shall include all classes of society to improve road users' behaviours, raising awareness and educating the public about safety belts, helmets, speed, safe crossing, respect for the traffic lights, leaving enough distance, sudden deviation and paying attention while driving, and other risks that cause traffic accidents. Moreover, the number of lectures, traffic exhibitions and awareness points that were implemented last year in Abu Dhabi reached around 766 programmes, benefiting an estimated 63,562 people at a daily rate of about two programmes. The Abu Dhabi programme to reduce traffic accidents called "together" has achieved great success on Facebook and YouTube among various classes of society. The total number of posts and comments on Facebook reached 6,234,347 comments and views, as well as awareness messages via Twitter reaching 800,000 users [13].

\section{Vehicle and Driver Safety}

Horberry [14] argues that "Many industrial domains are changing due to the increased uptake of automation or intelligent safety systems, whilst at the same time new operational methods for manufacture, mining, storage, service, transport or maintenance are being introduced. Such developments will undoubtedly change the uses of industrial mobile equipment, but the need to develop and maintain safe and efficient traffic management systems will surely remain." Kannan and colleagues [15] suggest the use of an ontology modelling approach in supporting drivers via safety warning messages at critical instances. Other significant safety technologies including adaptive cruise control and collision avoidance system, supporting the issue of warnings to drivers. Eichberger and Wallner [16] discussed that in Europe, ensuring traffic safety is an important issue because the economic burden of traffic accidents amounts to about 200 billion Euros a year. This study seeks to provide an overview of recent developments in relation to integrated vehicle safety. The focus of the study is on innovative ideas, styles, products and systems seeking to improve the present scenario. The combination of safety and comfort elements would be ensured in the future to ensure that systems would be beneficial during emergencies. The lack of vehicle crash protection installed on cars can also increase one's injuries during road crashes. This is especially seen in low- and middle-income countries, where vehicles may not have crash protective devices automatically installed in their vehicles. Failure to have these safety devices can increase the severity of these crashes [17]. Also, Intelligent Speed Adaptation (ISA) systems appeared more efficient at reducing speeds for drivers with experience on some road types. Experienced drivers' subjective satisfaction ratings of the systems remained stable over the assessment, whereas inexperienced drivers'ratings changed during the course of the study. There was slight evidence that drivers engaged in negative behavioural adaptation and no evidence that the use of ISA increased the subjective workload levels [18]. Moreover, in regard to an in-car tutoring system, the young drivers only made fewer violations if the system gave feedback messages, and even though they were convinced that the system had positive effects on traffic safety, they disliked it. In contrast, elderly drivers were pleased with the system. Elderly and young drivers expected a great traffic safety effect from enforcement and tutoring systems; $83 \%$ of the drivers expected a decrease in number of violations while an increase in safety was expected by $72 \%$ of the drivers [19]. Also John D. Lee [20] notes that young drivers could benefit tremendously from driver support systems. Extending proven approaches to enhance teen driving represents the most promising path for implementing new technology. A likely approach for Brovold et al. [21] to decrease the incidence of teen driver accidents and fatalities is through the use of vehicle-based intelligent driver support systems. To be most effective, the system should deal with the behaviours associated with an overwhelming number of fatal teen accidents. In-vehicle technology also offers a chance to address the matter of inexperience through enforcement of certain graduated driver's licence provisions.

\section{E. Emergency Response}

Kepaptsoglou et al. [22] discuss that in the current setting of persistent developments and demands for transportation, safety has become a major problem. Emergency response services are crucial in managing and decreasing the effect of traffic accidents and in saving human lives. The authors established an efficient emergency response plan in responding to traffic incidents. The goal was to strategically send emergency response vehicles within a large urban transportation area. They combined location models with a genetic algorithm and ensured location decisions via accident matrices including the frequency of accidents and impact for various areas of the network. They indicated the utility and application of this by applying it to Greece. In general, initial results indicate the efficacy of the programme. Noland [23] argues that overall results suggest impressive reductions in fatalities with improved and controlled medical care and technology. This has interesting implications for maintaining future reductions in fatalities and the possibility of attaining significant further improvements in several countries. The fatality reduction effects from these are likely quite substantial and a further understanding of these effects is beneficial for at least a couple of reasons. First, it provides a framework for understanding how to direct available resources for reducing traffic fatalities. Second, large reductions in traffic fatalities due to improvements in medical technology may often distort the analyses of other safety policies and may lead analysts to mistakenly conclude that some policies are more effective than they actually are. Johns et al. [24] discuss that the Abu Dhabi Police are tasked with the management of the delivery of the EMS and rescue during road accidents and although other providers are set to support the service, the main focus has been on the function of the police and the 
ambulance service. The speed of the emergency response and the level of clinical skills available at the scene affect general outcomes for patients and death rates.

\section{F. Objective}

The purpose of this paper is to analyse the perceptions of practitioners on the direct effects of the use of traffic safety technologies on other traffic safety dimensions, within Abu Dhabi highways. This paper provides the results of experts' survey. The analysis is organized based on the content and categorization of the survey questions:-

1) Can improvements in the deployment of traffic safety technologies have a positive impact on the efficiency of enforcement practices and improvements in traffic safety?

2) Can traffic safety technologies mitigate safety risks that may result from engineering and highway design shortfalls?

3) Is there a relationship between drivers' training and the efficiency of traffic safety technologies?

4) What are the direct effects of the use of traffic safety technologies on the efficiency of the operations of emergency services?

5) Does the use of safety technologies have the same impact levels on the following areas of interest:
a) Reduction in road accidents,
b) Mitigation of risks associated with engineering and highway design shortfalls,
c) Driver training and awareness,
d) Efficiency of emergency services?

\section{METHODOLOGY}

The decision was made to employ questionnaires as the most appropriate methodology for collecting the data because this was the only way possible to gather accurate data appropriate for the determination of the relationship between the use of traffic safety technologies, and to examine the direct effects of the use of traffic safety technologies on other traffic safety dimensions. The research strategy called for using web-based self- completion questionnaires for the overall population sample. The reason behind this selection was to get a sample frame in such way as to be unbiased, current and accurate. It was also intended to obtain a realistic view of the traffic safety experts with regard to the use of traffic safety technologies in the Emirate. Regarding the questionnaire sample, a contact list of traffic safety experts working within Abu Dhabi for at least five years in both the public and private sectors was obtained. A total of 165 experts were contacted by email, explaining the research objective and asking them to participate in a survey. Two follow-up email contacts were sent in an effort to increase the response rate, and in the end 107 experts participated in the survey and represented the sample. The survey was administered online using Gizmo Survey software to the stratified, specific sample population. The survey was conducted from July to September 2014 and the final data set contained 107 surveys, which was considered a good representation of the traffic safety experts in Abu Dhabi. The questionnaires was reviewed and validated before distribution by a panel of experts as a pilot study, namely, ten police traffic engineers with more than five years' experience at the Traffic and Patrols Directorate in Abu Dhabi. Their comments and recommendations were taken into consideration for the final questionnaire design. The methodology adopted for the analytical analysis of the survey data involved the applications of factor analysis and Friedman test techniques. Factor analysis is used to describe variability among observed and correlated variables and to detect structure in the relationships between variables, while the Friedman test is a nonparametric test for testing the difference between several related samples and in the analysis of variances when the same parameter has been measured under different conditions on the same subjects.

\section{DATA ANALYSIS AND DiSCUSSION}

The demographic profile of the experts who participated in the survey is presented in Table I. The majority of the experts had over 15 years of experience, having attained at least a masters' degree with a majority having gained considerable experience in UAE.

TABLE I. DEMOGRAPHIC PROFILE OF EXPERTS

\begin{tabular}{cccc}
\hline Group & Attribute & Number $(\mathrm{N})$ & Percentage $(\%)$ \\
\hline Occupation & Public sector & 74 & $68.5 \%$ \\
& Private sector & 34 & $31.5 \%$ \\
\hline Employer & AD Police & 42 & $38.9 \%$ \\
& DoT & 20 & $18.5 \%$ \\
& Municipality & 12 & $11.1 \%$ \\
& UPC & 2 & $1.9 \%$ \\
& Contractor & 16 & $14.8 \%$ \\
& Consultant & 12 & $11.1 \%$ \\
& Other & 4 & $3.7 \%$ \\
\hline Nationality & UAE & 36 & $33.3 \%$ \\
& GCC & 0 & $0.0 \%$ \\
& Other Arab & 40 & $37.0 \%$
\end{tabular}




\begin{tabular}{cccc}
\hline Group & Attribute & Number $(\mathrm{N})$ & Percentage $(\%)$ \\
\hline & Other countries & 26 & $24.1 \%$ \\
\hline Gender & Male & 106 & $98.1 \%$ \\
& Female & 2 & $1.9 \%$ \\
\hline Age range (in years) & $<30$ & 11 & $10.2 \%$ \\
& $30-40$ & 43 & $39.8 \%$ \\
& $41-50$ & 22 & $20.4 \%$ \\
& $51-60$ & 28 & $25.9 \%$ \\
& $>60$ & 4 & $3.7 \%$ \\
\hline Years of experience (in traffic safety) & $<5$ years & 18 & $16.7 \%$ \\
& $5-10$ years & 24 & $22.2 \%$ \\
& $11-15$ years & 17 & $15.7 \%$ \\
& $16-20$ years & 13 & $12.0 \%$ \\
& $21-25$ years & 15 & $13.9 \%$ \\
& $\geq 26$ years & 21 & $19.4 \%$ \\
\hline Years of experience in the UAE & $0-2$ years & 11 & $10.2 \%$ \\
& $3-5$ years & 14 & $13.0 \%$ \\
& $6-10$ years & 37 & $34.3 \%$ \\
& $10-14$ years & 14 & $13.0 \%$ \\
& $\geq 15$ years & 32 & $29.6 \%$ \\
\hline & Under graduate & 40 & $37.0 \%$ \\
& Masters & 51 & $47.2 \%$ \\
& PhD & 17 & $15.7 \%$ \\
\hline
\end{tabular}

RQ1. Can improvements in the deployment of traffic safety technologies have a positive impact on the efficiency of enforcement practices and improvements in traffic safety?

Six parameters, as presented in Table II, were included in factor analysis to determine the effects of deployment of various traffic safety technologies.

TABLE II. RQ1 FACTOR ANALYSIS VARIABLE PARAMETERS

\begin{tabular}{|l|l|}
\hline Code & Variable parameter \\
\hline P1 & Speed cameras can reduce number of accidents \\
\hline P2 & $\begin{array}{l}\text { Use of enforcement technologies increases drivers' } \\
\text { compliance }\end{array}$ \\
\hline P3 & $\begin{array}{l}\text { Warning signs for the presence of speed cameras are } \\
\text { important }\end{array}$ \\
\hline P4 & $\begin{array}{l}\text { Positive relationship between enforcement technologies } \\
\text { and reduction of accidents }\end{array}$ \\
\hline P5 & $\begin{array}{l}\text { Enforcement officers could be replaced by automated } \\
\text { enforcement technologies }\end{array}$ \\
\hline P6 & $\begin{array}{l}\text { Traffic safety technologies have direct effects on traffic } \\
\text { enforcement }\end{array}$ \\
\hline
\end{tabular}

Fig. 1 shows the factor loadings (on factor 1 and 2) for the six variables, as well as the loadings for the sample (participants), grouped based on their responses to the statement "Abu Dhabi highways need improvement in the field of traffic safety technologies".

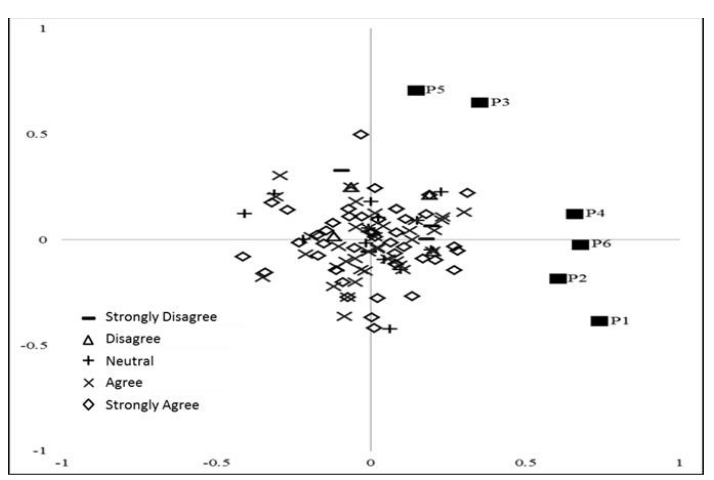

Figure 1. Plot of variable and sample factor loadings for RQ1
TABLE III. SUMMARY OF RESULTS FROM THE FACTOR ANALYSIS FOR RQ1

\begin{tabular}{|c|c|c|c|c|}
\hline Factor & Eigenvalues & $\begin{array}{c}\text { Total Variance } \\
(\%)\end{array}$ & $\begin{array}{c}\text { Cumulative } \\
\text { Eigenvalues }\end{array}$ & $\begin{array}{c}\text { Cumulative total } \\
\text { variance (\%) }\end{array}$ \\
\hline 1 & 1.958176471 & 0.326362745 & 1.958176471 & $32.64 \%$ \\
\hline 2 & 1.11992354 & 0.186653923 & 3.07810001 & $51.30 \%$ \\
\hline 3 & 1.017505759 & 0.169584293 & 4.09560577 & $68.26 \%$ \\
\hline 4 & 0.733908754 & 0.122318126 & 4.829514524 & $80.49 \%$ \\
\hline 5 & 0.675966774 & 0.112661129 & 5.505481298 & $91.76 \%$ \\
\hline 6 & 0.494518702 & 0.082419784 & 6 & $100.00 \%$ \\
\hline
\end{tabular}

RQ2: Can traffic safety technologies mitigate safety risks that may result from engineering and highway design shortfalls?

As can be seen in Fig. 1, all variables have positive factor 1 loadings, however variables P1, P2, P4 and P6 seem to be dominating this factor. These parameters encapsulate the relationships between safety technologies, enforcement, driver compliance and accident frequency. It can be inferred that the above aspects of traffic safety are interrelated and therefore it is the opinion of the experts that the deployment of traffic safety technologies can have a positive impact on the reduction of traffic accidents. Variables P3 and P5 are related to user awareness and replaced conventional enforcement, and although these two variables are closely correlated, it is not believed that they greatly affect the frequency of accidents. From the variance column in Table III, it can be seen that the first two factors explain $51 \%$ of the variability in all original variables, with factor 1 
achieving the highest reduction in dimensionality. In terms of the factor loadings of samples, no clear patterns can be observed and therefore expert opinions on the need for improvements in traffic safety technologies usage do not influence differently the variables of the analysis.

As part of RQ2, a Friedman test was carried out in order to establish variances in opinions about the effects that different safety technologies have in addressing various engineering and design shortfalls in Abu Dhabi's highway network. As can be seen in the results (Table IV) of the analysis, a statistically significant difference ( $\mathrm{P}<0.05$, highlight in dark grey) was observed on the effect that the three technologies have. However, in order to investigate further where these differences occur, Wilcoxon signed-ranks tests were performed on the different combinations of related group variables (speed cameras, VMS, and driver support systems). In doing so, a Bonferroni adjustment was used to calculate the new significance level as $\mathbf{P}=\frac{\mathbf{0 . 0 5}}{\mathbf{3}}=\mathbf{0 . 0 1 7}$. Based on the results (Table III, $\mathrm{P}<0.017$, highlighted in dark grey), driver support systems were found to be the least favourable measure amongst experts since there was a significant difference between driver support systems and VMS for all shortfalls and between driver support systems and speed cameras in most shortfalls. On the other hand, significant differences (apart from the case of the treatment of hazardous locations, cross-section treatment and roadside treatment) were reported when comparing speed cameras with VMS and therefore both measures can be used to mitigate the effects of accidents when inadequate highway designs exist.

TABLE IV. FRIEDMAN AND WILCOXON SIGNED-RANK TEST RESUltS FOR RQ2

\begin{tabular}{|c|c|c|c|c|c|c|c|}
\hline \multirow{2}{*}{$\begin{array}{l}\text { Engineering and design } \\
\text { shortfalls }\end{array}$} & \multicolumn{4}{|c|}{ Ranks - Friedman Test } & \multicolumn{3}{|c|}{ Wilcoxon signed-rank test } \\
\hline & $\begin{array}{c}\text { Speed cameras } \\
\text { (V1) }\end{array}$ & $\begin{array}{l}\text { Variable message } \\
\text { signs (V2) }\end{array}$ & $\begin{array}{l}\text { Driver support } \\
\text { systems (V3) }\end{array}$ & $\mathrm{P}$ & $\begin{array}{l}\mathrm{V} 1-\mathrm{V} 2 \\
(\mathrm{P})\end{array}$ & $\begin{array}{l}\text { V1-V3 } \\
(\mathrm{P})\end{array}$ & $\begin{array}{l}\mathrm{V} 2-\mathrm{V} 3 \\
(\mathrm{P})\end{array}$ \\
\hline $\begin{array}{c}\text { Treatment of hazardous } \\
\text { locations }\end{array}$ & 4.69 & 5.07 & 4.80 & .000 & .013 & .102 & .000 \\
\hline Cross-section treatment & 4.02 & 4.30 & 4.32 & .002 & .084 & .040 & .001 \\
\hline Roadside treatment & 3.96 & 4.20 & 4.36 & .003 & .138 & .039 & .000 \\
\hline Junctions treatment & 4.88 & 4.81 & 4.83 & .001 & .718 & .001 & .001 \\
\hline $\begin{array}{l}\text { Weaving section } \\
\text { treatment }\end{array}$ & 4.73 & 4.24 & 4.35 & .001 & .367 & .002 & .008 \\
\hline Ramp treatment & 4.41 & 4.51 & 4.39 & .000 & .637 & .001 & .000 \\
\hline Horizontal Alignment & 4.83 & 4.54 & 4.55 & .001 & .592 & .001 & .000 \\
\hline Vertical alignment & 4.48 & 4.32 & 4.40 & .003 & .701 & .009 & .004 \\
\hline
\end{tabular}

RQ3: Is there a relationship between drivers' training and the efficiency of traffic safety technologies?

TABLE V. FRIEDMAN AND WILCOXON SIGNED-RANK TEST RESULTS FOR RQ3

\begin{tabular}{|c|c|c|c|c|c|c|}
\hline \multirow{2}{*}{\multicolumn{2}{|c|}{$\begin{array}{l}\text { Drivers' training and the efficiency of traffic safety } \\
\text { technologies }\end{array}$}} & \multirow{3}{*}{$\begin{array}{c}\text { Ranks - Friedman } \\
\text { test } \\
1.87 \\
\end{array}$} & \multicolumn{2}{|c|}{ Friedman test } & \multicolumn{2}{|c|}{ Wilcoxon signed-rank test } \\
\hline & & & \multirow{2}{*}{$\frac{\mathrm{N}}{\mathrm{Chi}-\text { Square }}$} & \multirow{2}{*}{$\begin{array}{l}107 \\
5.817 \\
\end{array}$} & \multirow{2}{*}{$\frac{\mathrm{Z}}{-0.061}$} & \multirow{2}{*}{$\frac{\text { Asymp. Sig. }}{0.952}$} \\
\hline Variable 1 & $\begin{array}{l}\text { Effectiveness of traffic safety technologies } \\
\text { and a driver's training }\end{array}$ & & & & & \\
\hline Variable 2 & $\begin{array}{c}\text { Drivers' awareness about road hazards in } \\
\text { Abu Dhabi highways }\end{array}$ & 2.02 & Df & 2 & -2.636 & 0.008 \\
\hline Variable 3 & Additional training and awareness-raising & 2.11 & Asymp. Sig. & .055 & -1.811 & 0.70 \\
\hline
\end{tabular}

RQ4: What are the direct effects of the use of traffic safety technologies on the efficiency of the operations of emergency services?

As part of RQ3, a Friedman test was carried out in order to establish variances in opinions of the relationship between drivers' training / awareness and the efficiency of traffic safety technologies in Abu Dhabi's highway network. The null hypothesis considered in the Friedman test is that there are no differences between the influences of the three variables on the efficiency of traffic safety technologies. With a calculated $p$ $=.055>0.001$ (Table IV), the null hypothesis can be accepted as the results reveal a statistically significant relationship between drivers' training and the efficiency of traffic safety technologies. As there emerged no significant difference between the three variables, there is enough evidence to completely support the research hypothesis. However, the analysis does indicate that there is a differential rank ordered preference amongst the experts against the three variables and therefore, it is meaningful to conduct multiple comparisons in order to identify differences between the variables.

Post-hoc analysis with Wilcoxon signed-rank tests was also conducted with a Bonferroni correction applied, resulting in a significance level set at $\mathrm{p}<0.017$. As presented in Table IV, the results further confirm that there are no significant differences between variable 1 and variable 2 influences $(\mathrm{p}=0.952)$ or between variable 2 and variable 3 influences $(\mathrm{p}=0.070)$, despite an overall reduction in perceived influence of variable 3 versus variable 2 influences. However, there was a statistically 
significant reduction in perceived influence of variable 3 and variable $1(\mathrm{p}=0.008)$.

Four parameters, as presented in Table VI, which were derived from the questionnaire were included in factor analysis to determine the effect of the use of traffic safety technologies on the efficiency of the operations of emergency services.

TABLE VI. RQ4 FACTOR ANALYSIS PARAMETERS

\begin{tabular}{|c|l|}
\hline Code & \multicolumn{1}{|c|}{ Variable parameter } \\
\hline P1 & Enhancement of operators' efficiency \\
\hline P2 & Capability of taking appropriate and prompt action \\
\hline P3 & $\begin{array}{l}\text { Improvement of the response time of the emergency } \\
\text { vehicles }\end{array}$ \\
\hline P4 & $\begin{array}{l}\text { Notifications about accidents and effectiveness of } \\
\text { emergency responses }\end{array}$ \\
\hline
\end{tabular}

As can be seen in Fig. 2, all the variables have positive factor 1 loadings, however variable $\mathrm{P} 4$ seems to be the dominating factor. These parameters summarize the relationships between the use of traffic safety technologies and emergency responses. It can be inferred that the above aspects are interrelated and therefore it is the opinion of the experts that the deployment of traffic safety technologies can have a positive impact on enhancing the operator's efficiency and capability in taking appropriate and prompt actions in situations calling for emergency responses. The close approximation of $\mathrm{P} 1$ and $\mathrm{P} 2$ denote that these two parameters are closely correlated with regard to responses to emergencies. Therefore findings in terms of factor loading and parameter correlations can be considered to be significant. From the variance column in Table VI, it can be seen that the first factor (with an estimated Eigenvalue of 2.32) explains $57.9 \%$ of the variability amongst all the variables, with factor 1 achieving the highest reduction in dimensionality. In terms of the factor loadings of samples, there are observed clear patterns, and therefore expert opinions on the effectiveness of traffic safety technologies in enhancing the efficiency of the operations of emergency services are influenced by the variables of the analysis.

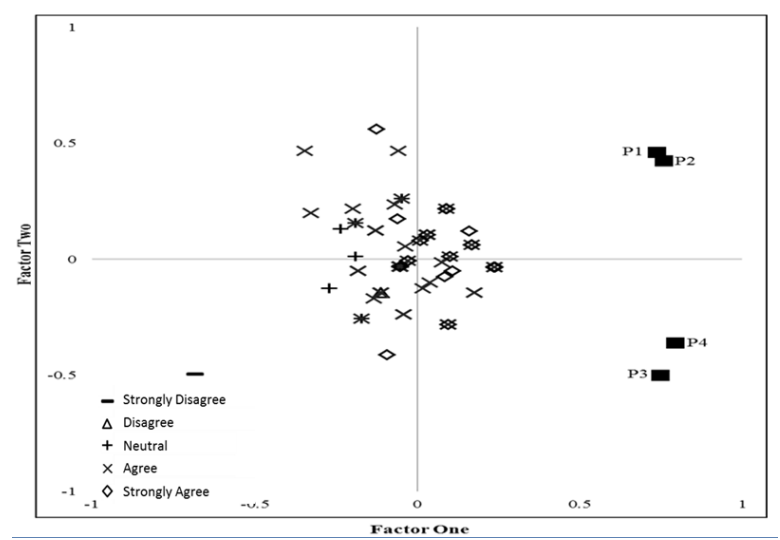

Figure 2. Analysis of experts' perceptions based on efficiency of the operations of emergency services in Abu Dhabi

In response to RQ5, a Friedman test was carried out in order to determine differences in experts' opinions regarding the level of impact of traffic safety technologies on the four variables. The null hypothesis considered in RQ5 is that there are no differences in the level of impact of traffic safety technologies on accident reduction, mitigation of risks associated to engineering and highway design shortfalls, driver training/awareness and in the efficiency of emergency services.

TABLE VII. SUMMARY OF RESULTS FROM THE FACTOR ANALYSIS FOR RQ4

\begin{tabular}{|c|c|c|c|c|}
\hline Factors & Eigenvalues & $\begin{array}{c}\text { Total variance } \\
(\%)\end{array}$ & $\begin{array}{c}\text { Cumulative } \\
\text { Eigenvalues }\end{array}$ & $\begin{array}{c}\text { Cumulative total } \\
\text { variance (\%) }\end{array}$ \\
\hline 1 & 2.315691 & 0.578923 & 2.315691 & $57.89 \%$ \\
\hline 2 & 0.771266 & 0.192816 & 3.086957 & $77.17 \%$ \\
\hline 3 & 0.536806 & 0.134202 & 3.623763 & $90.59 \%$ \\
\hline 4 & 0.376237 & 0.094059 & 4 & $100.00 \%$ \\
\hline
\end{tabular}

RQ5. Does the use of safety technologies have the same impact levels on the following variables:

a) Reduction of road accidents

b) Mitigation of risks associated with engineering and highway design shortfalls

c) Driver training and awareness

d) Efficiency of emergency services?

TABLE VIII. FRIEDMAN AND WILCOXON SigNED-RANK TEST RESUlts FOR RQ5

\begin{tabular}{|c|c|c|c|c|c|c|}
\hline \multirow{2}{*}{\multicolumn{2}{|c|}{$\begin{array}{l}\text { Does the use of safety } \\
\text { technologies have the same } \\
\text { impact levels on the } \\
\text { following variables? }\end{array}$}} & \multirow{2}{*}{$\begin{array}{l}\text { Ranks - } \\
\text { Friedman } \\
\quad \text { test }\end{array}$} & \multicolumn{2}{|c|}{$\begin{array}{c}\text { Friedman } \\
\text { test }\end{array}$} & \multicolumn{2}{|c|}{$\begin{array}{l}\text { Wilcoxon signed- } \\
\text { rank test }\end{array}$} \\
\hline & & & $\mathrm{N}$ & 107 & Z & $\begin{array}{l}\text { Asym } \\
\text { p. Sig. }\end{array}$ \\
\hline Variable 1 & $\begin{array}{l}\text { Reduction of } \\
\text { accidents }\end{array}$ & 2.49 & $\mathrm{~N}$ & 104 & -2.542 & 0.872 \\
\hline Variable 2 & $\begin{array}{l}\text { Engineering } \\
\text { and design } \\
\text { shortfalls }\end{array}$ & 2.19 & 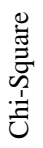 & 13.309 & -2.266 & 0.012 \\
\hline Variable 3 & $\begin{array}{l}\text { Drivers' } \\
\text { training }\end{array}$ & 2.66 & $t$ & 3 & -0.072 & 0.037 \\
\hline Variable 4 & $\begin{array}{l}\text { Effectiveness } \\
\text { of emergency } \\
\text { responses }\end{array}$ & 2.67 & 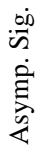 & .004 & -0.014 & 0.024 \\
\hline
\end{tabular}

As shown in Table VIII, the test results $p=.004>$ 0.001 indicate that there is no significant difference in the level of impact on traffic safety technologies on the analysis variables. The null hypothesis can be accepted that there is a statistically significant relationship between the impact levels of traffic safety technologies on the four variables under investigation. Nonetheless, the analysis results indicate that there are differential rank-ordered impact levels for the four variables and therefore a post-hoc analysis with Wilcoxon signed-rank tests was conducted with a Bonferroni correction 
(adjusted significance level set at $\mathrm{p}<0.017$ ) in order to identify differences between the variables.

The results demonstrate that there are statistically significant differences between the level of impacts of traffic safety technologies on variable 1 and variable 2 (p $=0.872$ ) or between variable 2 and variable 4 influences $(\mathrm{p}=0.012)$. However, despite an overall reduction in perceived level of impact on variable 2 versus variable 3, there is no significant reduction in impact levels of variable 1 and variable $4(\mathrm{p}=0.024)$ and variable 1 and 3 $(p=0.037)$. It should, however, be noted that these results do not present individual impact levels of the three categories (speed cameras, VMS and driver support systems) but rather a combined level of impact of the traffic safety technologies.

\section{CONCLUSION}

There emerged statistically significant relationships between the variables considered in the analysis and therefore all the five specific null hypotheses $\left(H_{O}\right)$ that were tested in this paper can be accepted. Based on this we can say that the deployment of traffic safety technologies has a positive impact on the efficiency of enforcement practices and improvements in traffic safety. The analysis has also revealed that deployment of enforcement technologies can reduce the number of accidents and increase driver compliance along the Abu Dhabi road network. Although the two variables user awareness and replaced conventional enforcement are closely correlated, it is not believed that they greatly affect the frequency of accidents. Also, the study found that speed cameras and VMS deployment are highly favoured in addressing engineering design shortfalls related to hazardous locations, cross-sections, junctions, weaving, and horizontal and vertical alignment. Further, driver training and awareness enhances the efficiency and effectiveness of traffic safety technologies, and the deployment of traffic safety technologies does have a positive impact on enhancing operators' efficiency and capability in taking appropriate and prompt action in situations calling for emergency responses. Moreover, there is a statistically significant relationship between the level of impact of the traffic safety technologies on accident reduction, mitigation of risks associated to engineering and highway design shortfalls, driver training/awareness and the efficiency of emergency services. However, the analysis did not determine the impact levels associated with the individual traffic safety technologies.

\section{REFERENCES}

[1] L. Åberg, "Traffic rules and traffic safety: Safety science 29, department of psychology," Uppsala University, Uppsala, Sweden, 1998, pp. 205-215.

[2] G. Chen, W. Meckle, and J. Wilson, "Speed and safety effect of photo radar enforcement on a highway corridor in British Columbia," Accident Analysis and Prevention, vol. 34, pp. 129$138,2002$.

[3] P. Stanojevi, D. Jovanovi', and T. Lajunenc, "Influence of traffic enforcement on the attitudes and behavior of drivers," Accident Analysis and Prevention, vol. 52, pp. 29-38, 2013.
[4] E. D. Pauw, S. Daniels, T. Brijs, E. Hermans, and G. Wets, "An evaluation of the traffic safety effect of fixed speed cameras," Safety Science, vol. 62, pp. 168-174, 2014.

[5] A. Montella, L. L. Imbriani, V. Marzano, and F. Mauriello, "Effects on speed and safety of point-to-point speed enforcement systems: Evaluation on the urban motorway A56 Tangenziale di Napoli," Accident Analysis and Prevention, vol. 75, pp. 164-178, 2015

[6] R. A. Retting, S. Y. Kyrychenko, and A. T. McCartt, "Evaluation of automated speed enforcement on Loop101 freeway in Scottsdale, Arizona," Accident Analysis and Prevention, vol. 40, pp. 1506-1512, 2008.

[7] S. G. Charlton, "The role of attention in horizontal curves: A comparison of advance warning, delineation, and road marking treatments," Accident Analysis and Prevention, vol. 39, pp. 873885, 2007.

[8] J. Castle, T. Sterling, A. Parkes, et al., Road Safety Engineering: Second Draft, Emirate of Abu Dhabi: TRL, 2010, pp. 44-49.

[9] A. Bener and R. Alwash, "A perspective on motor vehicle crash injuries and speeding in the United Arab Emirates," Traffic Injury Prevention, vol. 3, no. 1, pp. 61-64, 2002.

[10] US Department of Transportation. NHTSA, National Highway Traffic Safety Administration (2006). Fatalities facts: Traffic safety facts 2006 Data, USA. [Online]. Available: http://wwwnrd.nhtsa.dot.gov/Pubs/810809.pdf

[11] R. Christie, "The effectiveness of driver training as a road safety measure: A review of the literature," Noble Park, Victoria, Australia: Royal Automobile Club of Victoria (RACV) Ltd., 2001

[12] A. Parkes, N. Elsworth, S. Labbett, J. Fletcher, et al., Driver Training and Testing, Road safety strategy: Second Draft, Emirate of Abu Dhabi: TRL., 2010 pp. 62-71.

[13] Alittihad Newspaper (2013). Mortality reduction of traffic accidents in Abu Dhabi last year [Online]. Available at http://www.alittihad.ae/details.php?id=22941\&y=2013\&article=fu 11

[14] T. Horberry, "Safe design of mobile equipment traffic management systems," International Journal of Industrial Ergonomics, vol. 41, p. 559, 2011.

[15] S. Kannan, A. Thangavelu, and R. Kalivaradhan, "An intelligent driver assistance system (I-DAS) for vehicle safety modelling using ontology approach," International Journal of UbiComp, 1(3), 15-29, 2010.

[16] A. Eichberger and D. Wallner, "Review of recent patents in integrated vehicle safety, advanced driver assistance systems and intelligent transportation systems," Recent Patents on Mechanical Engineering, vol. 3, no. 1, pp. 32-44, 2010.

[17] National Technical University of Athens (2012). Best practice for cost-effective road safety infrastructure investments. Australasian College of Road Safety Conference [Online]. Available: http://www.cedr.fr/home/fileadmin/user_upload/Publications/200 8/e_Road_Safety_Investments_Report.pdf

[18] K. L. Young, M. A. Regan, T. J. Triggs, K. Jontof-Hutter, and S. Newstead, "Intelligent speed adaptation-Effects and acceptance by young inexperienced drivers," Accident Analysis and Prevention, vol. 42, no. 2010, pp. 935-943, 2013.

[19] D. De Waard, M. van der Hulst, and K. A. Brookhuis, "Elderly and young drivers' reaction to an in-car enforcement and tutoring system," Applied Ergonomics, vol. 30, pp. 147-157, 1999.

[20] J. D. Lee, "Technology and teen drivers," Journal of Safety Research, vol. 38, pp. 203-213, 2007.

[21] S. Brovold, N. Ward, M. Donath, and S. Simon, "The use of technology to address patterns of risk among teenage drivers," Journal of Safety Research, vol. 38, pp. 413-422, 2007.

[22] K. Kepaptsoglou, M. G. Karlaftis, and G. Mintsis, "Model for planning emergency response services in road safety," Journal of Urban Planning and Development, vol. 138, no. 1, pp. 18-25, 2011.

[23] R. B. Noland, "A review of the impact of medical care and technology in reducing traffic fatalities," IATSS Research, vol. 28 no. 2, pp. 6-12, 2004.

[24] B. Johns, J. Fletcher, J. Castle, et al., Emergency and Medical Care: Second Draft, Emirate of Abu Dhabi: TRL, 2010, pp. 149155. 
Dr. Musallem Al Junaibi is a researcher. He holds a Bachelor of Civil Engineering from United Arab Emirates University, a Masters degree in Management from Zayed University, and a $\mathrm{PhD}$ in Sustainability of Intelligent Transportation Systems from University of Wolverhampton. His main research interests include driver behaviour, sustainable transport, traffic safety, and intelligent transportation systems. He has been Senior Traffic Engineer at the Directorate of Traffic and Patrols in Abu Dhabi Police and is Head of Traffic Engineering and Roads Section. He serves on many committees related to traffic safety.

Dr. Georgakis obtained his PhD from Wolverhampton University for the development of a platform for the integration of intelligent transport systems. He has worked on a number of EPSRC and European FP research projects. Part of his postdoctoral work examined systems design integration for marine applications as part of the EU-FP VRShips Project. He has written for a number of peer-reviewed publications in areas such as intelligent transportation systems, integrated ICT platforms and frameworks, decision support systems and others. Current research interests involve the application of numerical methods and artificial intelligence techniques to the analysis of various measures and strategies and their performance on motorway and urban networks.
Professor Mushatat moved to academia, graduating firstly with a Diploma in Architecture before completing his PhD. He has taught architecture for 25 years, initially overseas and now in the UK as Professor of Architecture at the University of Wolverhampton. He held the post of head of schools of architecture and design in many countries of the Middle East. Concentrating mainly on the fields of architecture, environmental and sustainable design, construction and architectural education, he has had eight books published, as well as two textbooks, and about 80 research papers in refereed journals and conferences. $\mathrm{He}$ has produced several research reports, and compiled national and international presentations. Sabah has served on several national and international scientific bodies, such as the United Nations Environment Programme (UNEP), and the United Nations Educational, Scientific and Cultural Organization (UNESCO). He has worked as a consultant for the governments of both Holland and Germany, and served as a member of seven editorial boards of international journals. Professor Mushatat is the organiser of the prestigious Ajman International Urban Planning Conference (AIUPC), which is held every year in UAE. 